\title{
A utilização de subcoberturas na construção civil para a correção do comportamento térmico de sistemas de coberturas cerâmicas: uma avaliação experimental
}

\section{The use of foils in the construction industry for the correction of the thermal behavior of roofing systems: an experimental evaluation}

\author{
Francisco Vecchia ${ }^{1}$
}

Resumo

O artigo trata de experimento de campo, tendo sido ensaiada a colocação de lâminas de alumínio estruturado foil (subcoberturas) como medida de correção ambiental do comportamento térmico de uma edificação ocupada. Considerando a inexistência de modelos adequados que simulem quantitativamente o efeito de isolamento térmico provocado por lâminas metálicas, de cor clara, na forma de barreira de radiação, optou-se por desenvolver e aplicar um sistema empírico de medição automático, por meio da utilização de termopares tipo T e datalogger CR10X, Campbell Scientific. Foram então registradas e verificadas as flutuações das temperaturas superficiais e do ar, registradas no interior da referida edificação ocupada, antes e depois da instalação de lâminas de alumínio brilhante dupla face, estruturado para resistir esforços mecânicos, como medida de redução do fluxo térmico pelo sistema de cobertura: forro de madeira Pinus elliottis, subcobertura de alumínio e telhas cerâmicas. Além disso, foi utilizado o conceito de ritmo climático para a escolha de dois períodos de medição, em episódios de verão, assim como dos dias típicos representativos do ensaio, antes e depois da colocação das laminas de alumínio estruturado.

Palavras-chave: Comportamento térmico de coberturas. Barreiras de radiação de alumínio (foil). Minimização da carga térmica.

\begin{abstract}
This article deals with a field experiment, having tested foils as a measure of environmental correction of the thermal behavior of an inhabited construction. Considering the inexistence of suitable models that simulate quantitatively the effect of thermal isolation caused by light-coloured metal foils, in a thermal-barrier form, it was chosen to develop and use a measurement automatic empirical system, by means of the use of type $\mathrm{T}$ thermopairs and datalogger CR10X, Campbell Scientific. It was then registered and verified the fluctuations of the surface and air temperatures, registered inside the above mentioned inhabited construction, before and after the installation of double-faced bright foils, structured to resist mechanical strengths, as a way of reducing the thermal flow by the covering system: wood ceiling, Pinus elliottis, foils and ceramic tiles. Furthermore, it was used the climatic rythm concept for the choice of two measurement periods, in summer episodes, as well as of the typical days which represent this study, before and after the placing of foils.
\end{abstract}

Key words: Thermal behavior of roofs; aluminium thermal barriers (foils); heat load minimization.

\footnotetext{
1 Centro de Recursos Hídricos e Ecologia Aplicada.Departamento de Hidráulica e Saneamento. Escola de Engenharia de São Carlos, Universidade de São Paulo.São Carlos - Brasil. Email. fvecchia@sc.usp.br
} 


\section{Introdução}

A principal intenção deste artigo, por um lado, é a de mostrar resultados experimentais do comportamento térmico de uma habitação ocupada, antes e depois, da colocação de isolamento térmico por reflexão ${ }^{2}$, também. Esse isolamento que também é denominado barreira de radiação (foil), foi aplicado ao sistema de cobertura composto por telhas cerâmicas e por forro de madeira Pinus elliottis. Por outro, intenta evidenciar a objetividade de aplicação dos conceitos da Climatologia Dinâmica para a definição de um dia típico representativo do clima adotado para o estudo, em função do ritmo climático, da estação do ano e das condições do tempo (meteorológico) atuantes nos períodos dos ensaios realizados.

As trocas térmicas pelos diferentes sistemas de coberturas constituem, nas edificações térreas, a principal causa do inadequado comportamento térmico e da ocorrência de estresse térmico, prejudicando a otimização das atividades desenvolvidas nesses ambientes. As medidas de correção por meio de condicionamento do ar são as causas de diversas doenças e do excessivo consumo de energia elétrica, sejam elas medidas de calefação ou de refrigeração. O presente artigo apresenta os resultados de ensaio experimental realizado em habitação ocupada, após a aplicação de isolamento por reflexão (barreira de radiação) em sua reação frente ao calor incidente do exterior.

Os ensaios foram realizados antes da colocação das lâminas de foil e, posteriormente, logo após período mínimo de dez dias, guardados para respeitar o efeito da estabilização interna das temperaturas. Para a discussão dos resultados encontrados, aplicouse o conceito de dia representativo com base na definição da Organização Mundial de Meteorologia, de que o clima expressa a totalidade de elementos meteorológicos que, em suas sucessões habituais e em um dado período, caracteriza o estado da atmosfera.
A abordagem utilizada para determinar os períodos de análise está baseada em critérios da Climatologia Dinâmica e no conceito de ritmo climático introduzido por Monteiro (1973), segundo o qual o clima pode ser considerado como sucessão encadeada e sucessiva de sistemas atmosféricos. Os resultados obtidos na avaliação do comportamento térmico antes e depois da colocação do foil estão apresentados na forma de dias típicos representativos do clima. Foram considerados em função da circulação atmosférica no Sudeste brasileiro e de suas repercussões sobre o Ambiente Construído, segundo Vecchia (1997), por meio da categoria taxonômica espacial microclimática.

Os dias representativos procuram traduzir a resposta térmica do sistema de cobertura em função das excitações impostas pelas variações climáticas que ocorrem ao longo do episódio climático definido para a análise. O episódio pode ser entendido como período típico de uma dada época do ano, que procura expressar peculiares situações, críticas ou não, para o desempenho térmico de edificações.

Em sua resposta ou reação frente ao calor, a principal forma de transmissão do fluxo térmico para o interior da edificação analisada ocorre na forma de radiação, forma primária de transferência de calor. A energia solar atinge as telhas e a parte absorvida pelo material cerâmico é então transmitida, pela telha, por meio de condução térmica, ao interior da edificação.

Em função do aumento da aplicação das barreiras de radiação em edificações residenciais e devido à dificuldade de referências técnicas sobre o assunto, a investigação realizada procurou, de forma experimental, aplicar e analisar os resultados obtidos em caso real. O experimento escolhido foi uma habitação ocupada, onde se estudou os valores das temperaturas internas do ar e das superficiais, antes e depois da aplicação das lâminas de foil.

2 O isolamento térmico por reflexão ou barreiras de radiação, na forma de subcobertura, é composto por lâminas de alumínio estruturado, em ambas as faces do material, com resistência mecânica e também se denomina foil. Deve ser aplicado acima do forro e abaixo das telhas. Ressalte-se que para a sua adequada atuação é preciso garantir a existência de um espaço ou câmara de ar superior à face aluminizada refletora. 
Para referenciar as condições de realização dos ensaios, antes e depois, foi aplicado o conceito de episódios representativos do clima e deles extraídos os dias típicos, também, representativos das condições do tempo atmosférico. Para isso, foram consideradas as propriedades das massas de ar atuantes: domínio de sistemas atmosféricos semelhantes nos distintos, porém, similares períodos de tempo analisados nos ensaios térmicos.

Os sistemas atmosféricos atuantes considerados nos ensaios, realizados no verão, foram massas de ar, tropical Atlântica-mTA, nessa época, de característica úmida com ocorrência de nebulosidade e com temperatura média na faixa dos $21.5^{\circ} \mathrm{C}$. Os valores normais da temperatura média máxima e da temperatura média mínima, respectivamente, estão em torno de $27.5^{\circ} \mathrm{C}$ e $18.0^{\circ} \mathrm{C}$, segundo as Normais Climatológicas da região de São Carlos (SP). Ressalte-se ainda que as temperaturas absolutas, máxima e mínima, historicamente registradas foram, respectivamente, $35.7^{\circ} \mathrm{C}$, ocorrido em 27/01/1971 e $8^{0} \mathrm{C}$ em 11/01/1970.

\section{Material e Métodos}

Caracterização do clima. As condições do tempo (meteorológico) no período de medições do comportamento térmico do sistema de cobertura

Segundo Vecchia (1997), a descrição das condições atmosféricas se faz necessária para a escolha dos episódios do fato climático, tomados para caracterizá-los como representativos do clima em que ocorreu a análise do comportamento térmico. Foram tomados dois episódios da estação de verão, objetivando a avaliação do comportamento térmico, antes e depois da correção térmica proposta (foil), aplicado sob as telhas e acima do forro de madeira de Pinus elliottis, de cor clara. Os dois episódios utilizados para as medições procuram comparar a reação do sistema de cobertura frente ao calor.

\section{Condições climáticas antes da colocação do foil}

JANEIRO: O destaque do mês de janeiro 2001, de acordo com o INPE, foram chuvas com valores abaixo da média observadas na Região Sudeste, Centro-Oeste e Nordeste do País, com ênfase para o Estado de São Paulo e sul de Minas Gerais. Isso permitiu a ocorrência de céu claro, o que implica em maior penetração da radiação solar global, nessa época, com registros tomados na faixa de 1000 a $1200 \mathrm{~W} / \mathrm{m}^{2}$.

Ainda segundo o INPE (2001), a anomalia das chuvas de janeiro dos últimos três anos, sobre a Região Sudeste do Brasil, permitiu observar que o mês de janeiro de 2001 foi o mais seco dos últimos três anos, com chuvas em torno de $100 \mathrm{~mm}$ abaixo da média. Destacam-se, segundo o INPE (2001), os seguintes eventos durante janeiro de 2001.

- Sete frentes frias atingiram o Brasil, enquanto a média climatológica, para o referido mês, é de seis sistemas atmosféricos atuantes. Esses sistemas se deslocaram rapidamente pela Região Sul, chegaram ao litoral da Região Sudeste, com intensidade fraca e, posteriormente, se deslocaram para o oceano Atlântico.

- Um único episódio de Zona de Convergência do Atlântico Sul (ZCAS) foi observado sobre a região Sudeste do Brasil, no início do mês, entre os dias $1^{\underline{0}}$ e 5 de janeiro, organizando uma faixa de nebulosidade e de chuvas isoladas.

- A presença freqüente do Vórtice Ciclônico em Altos Níveis (VCAN), sobre a Região Central do país e Oeste do Nordeste, inibiu a formação de nuvens e reduziu as chuvas.

\section{Condições climáticas depois da colocação do foil.}

FEVEREIRO: No mês de fevereiro, também, segundo o INPE (2001), massas de ar quente e seco contribuíram para a escassez das chuvas no Brasil. As chuvas no mês de fevereiro tiveram 
comportamento similar ao de janeiro. A precipitação, igualmente, ficou abaixo da média histórica em quase todo o país. As regiões com menores índices pluviométricos foram: o Nordeste, quase todo o Sudeste e Centro-Oeste. Os sistemas meteorológicos que atuaram sobre o país, em fevereiro, foram:

- Sete frentes frias de fraca intensidade provenientes do sul do continente se afastaram, para o oceano no litoral do Rio de Janeiro. Estes sistemas fracos conseguiram organizar poucas chuvas em forma de pancadas no interior do país. Esse fato também permitiu a penetração da radiação solar global em condições de céu limpo ou de pouca nebulosidade. Também contribuiu para a penetração da radiação solar a presença frequiente do Vórtice Ciclônico em Altos Níveis (VCAN) que inibiu a formação de nuvens e, consequentemente, reduziu as chuvas sobre a maior parte do país. Na Região Sudeste, as frentes frias tiveram deslocamento pelo litoral e organizaram reduzida nebulosidade e convecção. As chuvas ocorreram em forma de pancadas, principalmente, no período da tarde e ao anoitecer. A Alta Subtropical sobre o continente também inibiu a ocorrência das chuvas. Esse quadro resultou em valores superiores a $100 \mathrm{~mm}$ abaixo da média em quase toda a região, INPE (2001).

\section{Descrição do equipamento de aquisição de dados}

Para a aquisição e o armazenamento de dados, foi utilizado datalogger programável CR1OX, Campbell Scientific Inc., com bateria acoplada, que permite autonomia em campo, aquisição com comandos e medição para dados analógicos e digitais. Foi utilizado multiplexador AM 432, composto por 32 canais para colocação de cabos termopar tipo $\mathrm{T}$ e de termístor de referência para substituição de junta fria.

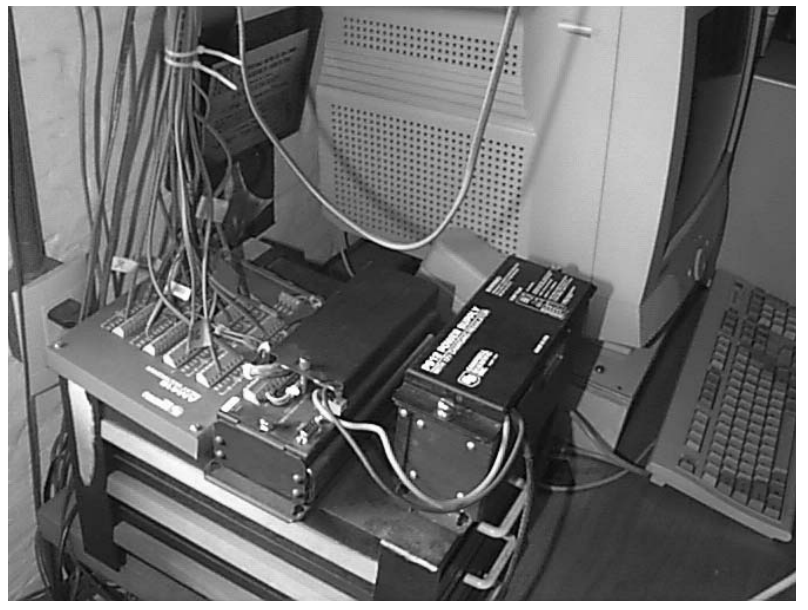

Figura 1. Vista geral do sistema de aquisição automática de dados, composto por datalogger CRIOX Campbell Scientific Inc., com multiplexador de sinais acoplado AM 416 e sistema de bateria e filtros de tensão. Na figura podese observar, à esquerda, os cabos axiais azuis que são os termopares tipo T. À direita e ao fundo vista parcial do computador servidor do sistema de aquisição.

\section{Sensores}

Nas medições realizadas foram empregados termopares tipo T, (cobre-constantin), 2x24AWG, Norma ANSI, com pontas eletro-soldadas em ambiente de argônio e os sensores de temperatura protegidos por abrigos constituídos por tubos de PVC de $100 \mathrm{~mm}$ de diâmetro. A colocação de cada um dos sensores determinada pela altura máxima da zona habitada, neste experimento, definida a $1.50 \mathrm{~m}$ do piso.

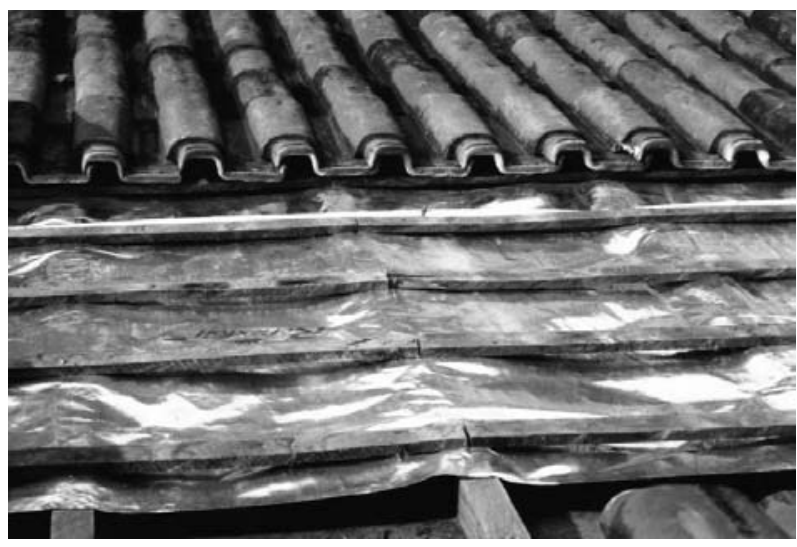

Figura 2. Colocação das lâminas sob as ripas e telhas 


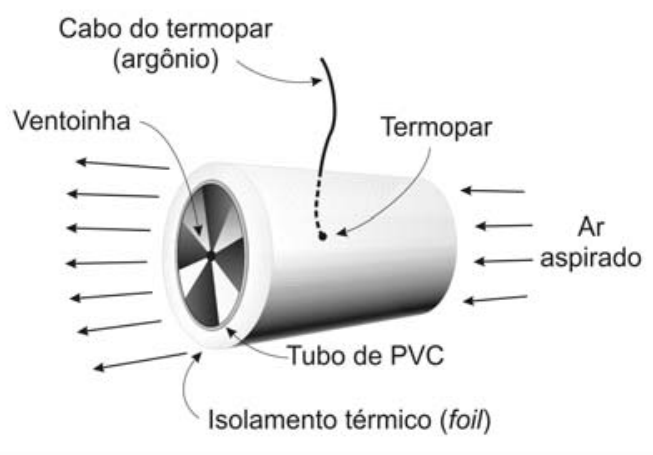

Figura 3. Sistema de abrigo (proteção) com ar aspirado, composto por tubo de PVC, $150 \mathrm{~mm}$ de diâmetro, comprimento de $250 \mathrm{~mm}$ e envolto com isolamento térmico (barreira contra radiação) de alumínio estruturado brilhante, onde se colocam os termopares tipo T. Esse sistema evita o efeito indesejado da radiação na leitura dos valores da temperatura do ar

\section{Método de Medição}

A coleta de dados estabelecida no ensaio se baseou em recomendações da Organização Mundial de Meteorologia, que estabelece intervalos de aquisição de registros horários. No entanto, foram utilizados intervalos mais reduzidos; tomado-se três registros por minuto, portanto com intervalos de 20 segundos entre uma medição e outra, com a totalização em médias a cada meia hora.

\section{Aquisição, armazenamento e tratamento de dados}

Os registros armazenados no datalogger CRIOX foram semanalmente descarregados em computador, na forma de arquivos dat, separados por vírgula e, posteriormente, transformados em arquivos $x l s$. Separados em planilhas diárias, os registros foram analisados em sua consistência, antes de serem lançados na planilha definitiva, contendo os gráficos de temperaturas do ar e superficiais.

\section{Gráficos e planilhas MS Excel}

A partir de planilhas, contendo os dados obtidos, foram então efetuados os gráficos diários compreendendo as temperaturas externa do ar; temperaturas superficiais interiores, assim como as temperaturas do ar internas, todas registradas com sensores termopares, protegidos por abrigos de PVC. Registre-se que os valores das temperaturas do ar exteriores foram colhidos à sombra e em dispositivos de proteção similares aos da temperatura interna, porém, providos de aspiração do ar. Testes experimentais indicaram diferença de até $5^{\circ} \mathrm{C}$ entre as temperaturas tomadas nos abrigos sem proteção (isolamento com lâminas de alumínio) e sem aspiração do ar exterior, que ocorrem em função da ação da radiação solar incidente e da velocidade do vento exterior sobre o abrigo.

Da mesma forma, procurou-se verificar o efeito conjunto e separado da ação dos ventos sobre esses dispositivos de aquisição de dados. Os dois efeitos indesejados na medição das temperaturas do ar foram minimizados, ao máximo, por meio da colocação de isolamento térmico no revestimento do abrigo e, também, pela aspiração do ar no interior desses dispositivos.

\section{Descrição do sistema de cobertura e das laminas de alumínio estruturado (foil)}

O sistema de cobertura se compõe de telhas cerâmicas tipo capa-canal, apoiadas sobre madeiramento tradicional (terças, caibros e ripas). As lâminas de alumínio foram colocas sobre os caibros de $0.50 \times 0.50 \mathrm{~m}$ e, portanto, abaixo das ripas de $0.25 \times 0.15 \mathrm{~m}$, formando pequena câmera de ar entre of foil e as telhas cerâmicas. A existência dessa câmara de ar é essencial para que o foil possa atuar como barreira de radiação no processo de isolamento térmico de coberturas.

\section{Descrição da barreira de radiação aplicada (foil)}

As características técnicas das lâminas de foil aplicado no ensaio são as seguintes, de acordo com informações fornecidas pelo fabricante: a refletividade se situa em torno de $95 \%$ e a 
emissividade é de aproximadamente 0.03. A lâmina possui $0.18 \mathrm{~mm}$ de espessura e é composta por dupla face de alumínio reforçada. A dupla face faz com que a barreira de radiação (foil) atue nos dois sentidos do fluxo térmico, exterior-interior-exterior. Dessa forma, o fluxo é amortecido na reação frente ao calor (períodos quentes - verão - dia) e na reação frente ao frio (períodos frios - inverno - noites).

\section{Descrição da edificação ensaiada.}

A edificação utilizada no experimento, trata-se de residência ocupada, que foi implantada no terreno de acordo com as recomendações de adequação térmica ao clima local. Está orientada no sentido Norte-Sul, fachadas maiores, para evitar a radiação solar do período da tarde, privilegiando a fachada norte para incidência de luz solar no período de inverno e, na fachada sul, minimizando essa incidência no período de verão, principalmente no que se refere às janelas.

Possui massa térmica considerável, com paredes de $0.25 \mathrm{~m}$ de espessura (tijolos cerâmicos maciços de $0.25 \times 0.10 \times 0.05 \mathrm{~m}$ ), sistema de ventilação cruzada com incidência do fluxo de ventos com ângulo de $45^{0}$ em relação aos ventos predominantes na região, que são os ventos de Nordeste (NE) no domínio da massa Tropical Atlântica (mTA) e dos ventos secundários de Sudeste (SE) no domínio da massa Polar Atlântica (mTA).

\section{Resultados}

Descrição do problema térmico da residência. Resposta frente ao calor.

A residência utilizada no ensaio experimental apresentava excessivo calor no período vespertino, notado pela percepção de desconforto nesse período. Para verificar quantitativamente os valores das temperaturas internas foram colocados termopares do tipo T (cobre-constantin) para medir os valores da temperatura superficial do forro de madeira (Pinus elliottis) e os valores da temperatura interna do ar (temperatura de bulbo seco).

O dia 7 de janeiro foi escolhido dentro de um episódio de aproximadamente sete dias em que houve a atuação de uma massa Tropical Atlântica-mTA, com reduzida nebulosidade e valores da radiação solar global, compatíveis com a variação esperada para o verão. Tomado de modo similar, assume a forma aproximada de parábola peculiar ao período atmosférico.

A curva formada, de aparência senoidal, é peculiar à temperatura externa do ar e evidencia que a nebulosidade não afetou significativamente a sua variação diária, com esperada elevação a partir do nascer do sol e, conseqüente, decréscimo após o pôrdo- sol. No período de medições, segundo o INPE, houve redução da nebulosidade e de chuvas, abaixo do habitual.

\section{DIA 07 JANEIRO}

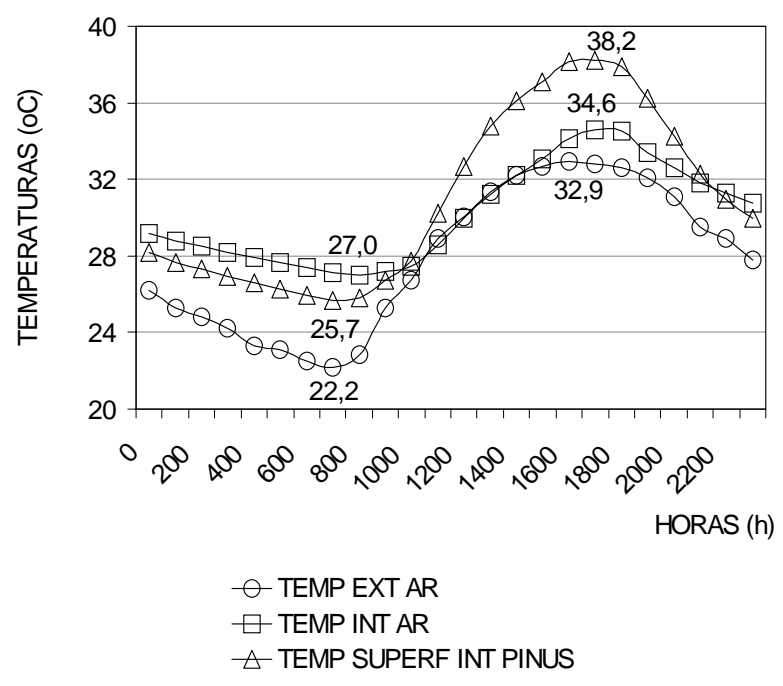

Figura 4. Dia típico experimental de verão.

Antes da colocação do isolamento térmico, por barreiras de radiação, por meio de lâminas de foil. O gráfico apresenta os valores horários das temperaturas externa do ar, das temperaturas internas do ar e superficial de forro de madeira.

A temperatura do ar interna registrada no dia 7 segue a senóide da temperatura externa. No período 
vespertino (após as 15 horas), foram registrados valores mais elevados, tendo sido alcançado o valor máximo de $34.6^{\circ} \mathrm{C}$.

Da mesma forma, a curva de aspecto senoidal da temperatura superficial do forro de Pinus elliottis atinge valores mais elevados, principalmente a partir das 11 horas, momento em que começa a se elevar até atingir o seu máximo, às 16 horas, com valor igual a $38.2^{\circ} \mathrm{C}$. Portanto, no momento crítico do período da tarde, tem-se uma diferença de $36^{\circ} \mathrm{C}$ em relação ao valor máximo da mais elevada temperatura do ar exterior. Com respeito ao valor da mais elevada temperatura superficial, a diferença registrada foi ainda maior, chegando aos $5.3^{\circ} \mathrm{C}$.

Ao longo do período vespertino, que é o período termicamente crítico, pôde-se observar que em um dia típico experimental, de verão, a partir das 11 horas, os valores da temperatura superficial do forro de madeira inicia a sua elevação, que atinge níveis acima dos $30^{\circ} \mathrm{C}$, ao longo de todo esse período. $\mathrm{O}$ valor máximo registrado foi de $38.2^{\circ} \mathrm{C}$. Esses valores contribuem para elevar a temperatura interna do ar, o que é justificado pelo fato de não existir, na edificação ensaiada no experimento, a penetração de radiação solar direta por nenhuma superfície envidraçada que produza o efeito estufa.

O calor transmitido internamente ocorre tão somente pela transmissão por condução pelas paredes e pela cobertura. $\mathrm{O}$ valor máximo registrado para a temperatura superficial das paredes foi de $31^{\circ} \mathrm{C}$, abaixo de todas as temperaturas internas. Esse valor é menor que o obtido para o ar exterior, de onde se conclui que sua participação não é decisiva no processo de transmissão de calor excessivo para $\mathrm{o}$ interior da residência.

A temperatura do ar interna a partir das 11 horas também acompanha, com valores similares, a ascensão da temperatura externa do ar até as 15 horas, quando então começa a elevar-se, atingindo valores superiores aos da temperatura externa, até alcançar o seu valor máximo, em torno de $34.6^{\circ} \mathrm{C}$. A temperatura externa do ar atinge o seu maior valor que é de $32.9^{\circ} \mathrm{C}$.
Para tal condição de ganhos térmicos em situação de verão, ainda apontada com registros experimentais, tornava-se necessária a adoção de medidas de atenuação térmica. Identificado o sistema de cobertura como elemento de mais evidente troca térmica, optou-se por escolher o isolamento por reflexão como o elemento de isolamento térmico, devido ao caráter do sistema construtivo da cobertura. As lâminas de foil se apresentavam como a mais adequada solução construtiva, também devido à falta de espaço e em função das condições da estrutura de telhado.

\section{DIA20 FEVEREIRO}

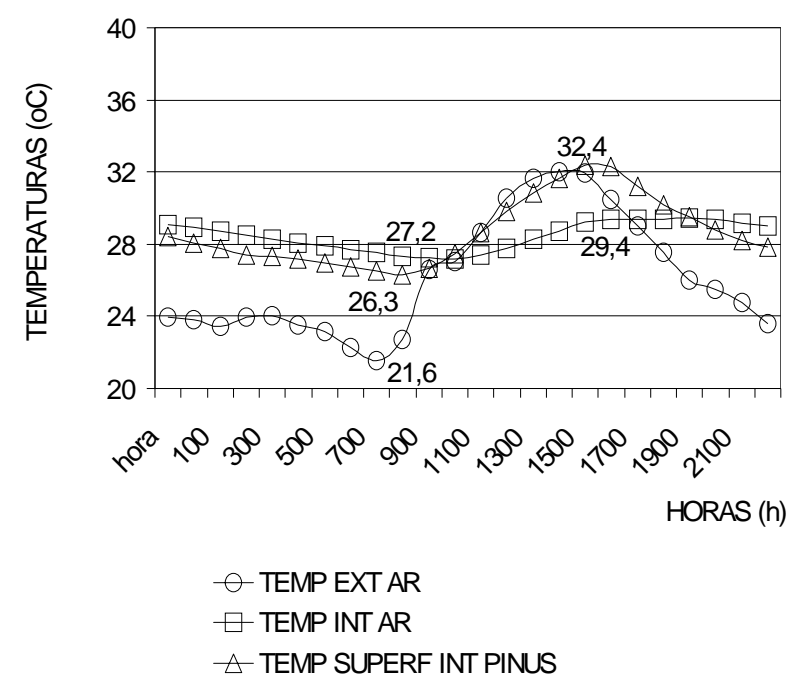

Figura 5. Dia típico experimental, depois da colocação do foil

Nota-se que os valores das temperaturas interiores não mais ultrapassam, no período vespertino, os valores registrados para a temperatura externa do ar. Ressalte-se ainda a redução dos valores horários da temperatura superficial do forro de madeira (Pinus elliottis) que, dessa forma, contribui para reduzir os valores da temperatura do ar interna.

As lâminas foil foram colocadas sob as telhas cerâmicas, em dia típico experimental escolhido por se encontrar sob o domínio da massa Tropical 
Atlântica-mTA, com alguma nebulosidade e com curvas de temperaturas similares ao do primeiro período de ensaios realizados. As curvas das temperaturas do ar interior e das temperaturas superficiais do forro de Pinus elliottis seguem também a forma de senóide esperada, porém, apresentam valores menores ou iguais aos da temperatura externa, o que ocorre somente após as 10 horas.

No período da tarde, os valores da temperatura superficial seguem inferiores aos da temperatura externa até atingir o pico máximo às 15 horas, quando então atingem valores iguais e valem $32.4^{\circ} \mathrm{C}$. As temperaturas internas do ar também seguem abaixo dos valores da temperatura externa, até se igualarem às 17 horas, com valor de $29.5^{\circ} \mathrm{C}$, quando a temperatura externa do ar se encontra em franco declínio.

No momento de maior calor, a temperatura externa e a superficial interna do forro de Pinus são iguais e valem $32.4^{\circ} \mathrm{C}$. O valor da temperatura do ar interna é de $29.3^{\circ} \mathrm{C}$. Isso mostra uma diferença de $3.0^{\circ} \mathrm{C}$ entre elas, evidenciando que, a partir da colocação das lâminas de foil, as temperaturas internas do ar não mais atingirem valores maiores que as do ar exterior, salvo raras situações excepcionais. Portanto, no período vespertino, a tendência após a colocação do foil é a de se registrarem temperaturas internas do ar menores ou iguais às das temperaturas que ocorrem exteriormente.

Registre-se, ainda, que houve uma redução de $5.8^{\circ} \mathrm{C}$ na temperatura superficial máxima do forro de Pinus elliottis, após a aplicação das lâminas de foil. Na reação frente ao calor, que ocorre no período vespertino, a diferença entre as temperaturas interiores registradas, antes e depois do foil, foi de $5.2^{\circ} \mathrm{C}$. Isso sob condições similares de radiação solar global e das temperaturas externa do ar, conforme indicam os gráficos anteriores. Saliente-se ainda que os valores das temperaturas externas do ar são decorrentes das propriedades da massa de ar atuantes sobre a região, no caso, mTA.

\section{Discussão}

\section{Resposta ou reação frente ao calor}

A aplicação do foil, como subcobertura, contribuiu para a redução dos valores da temperatura superficial do forro de madeira e da temperatura interna do ar. Escolhido pela sua aplicabilidade em espaço reduzido existente sob as telhas cerâmicas e o forro de madeira, mostrou-se eficiente na redução da carga térmica transmitida ao interior da residência.

A tabela 1, resume os valores das temperaturas antes e depois da aplicação do foil, na forma de subcobertura isolante por criar barreiras de radiação. A temperatura superficial do forro de madeira foi reduzida em $5.8^{\circ} \mathrm{C}$, o que contribuiu para diminuir a temperatura do ar interior em $5.2^{\circ} \mathrm{C}$. Apesar das elevadas temperaturas externas do ar, que ocorrem devido à atuação da massa Tropical Atlântica e dos valores da radiação solar global, maiores e com maior tempo de duração, nessa época do ano, a aplicação do foil reduziu significativamente os valores da temperatura interna do ar.

Antes da colocação do foil, no período da tarde, as temperaturas do ar interiores ascendiam praticamente iguais as do ar exterior entre 11 e 15 horas, com valores entre 28 e $34^{\circ} \mathrm{C}$. A partir desse horário, a temperatura do ar interna seguia mais elevada até às 21 horas, com valores superiores aos $32^{\circ} \mathrm{C}$. Este fato assegurava ao período vespertino a ocorrência de estresse térmico, obrigando a utilização de condicionamento do ar, ou mesmo, de inadequação para uso nesse referido período. 
Tabela 1. Resumo dos valores obtidos nas medições realizadas entre 11 e 15 horas.

\begin{tabular}{|l|c|c|c|}
\hline & ANTES & DEPOIS & $\begin{array}{c}\triangle \mathrm{t} \text { (Redução } \\
\text { térmica })\end{array}$ \\
\hline $\mathrm{t}$ superficial interna $\max \left({ }^{\circ} \mathrm{C}\right)$ & 38.2 & 32.4 & 5.8 \\
\hline $\mathrm{t}$ interna do ar max $\left({ }^{\circ} \mathrm{C}\right)$ & 34.6 & 29.4 & 5.2 \\
$\triangle \mathrm{t}\left({ }^{0} \mathrm{C}\right)$ & 3.6 & 3.0 & \\
\hline $\mathrm{t}$ externa do $\operatorname{ar} \max \left({ }^{\circ} \mathrm{C}\right)$ & 32.9 & 32.4 & 0.5 \\
\hline
\end{tabular}

Após a colocação das lâminas de alumínio, os valores da temperatura do ar interiores se apresentaram mais reduzidas, não mais atingindo os $30^{\circ} \mathrm{C}$, valor que pode ser indicativo do início de períodos propícios ao estresse térmico por calor excessivo. Conforme mostra o quadro anterior, a temperatura superficial máxima foi reduzida de 38.2 para $32.4^{\circ} \mathrm{C}$, ou seja, um $\Delta \mathbf{t}=\mathbf{5 . 8}^{\circ} \mathbf{C}$, portanto de quase seis graus Celsius. Redução semelhante também ocorreu com a temperatura máxima do ar interior que ficou 5.2 graus Celsius menor, após a colocação do foil, passando de 34.6 para $29.4^{\circ} \mathrm{C}$.

Esse valor em torno de $29.5^{\circ} \mathrm{C}$ pode ser considerado próximo aos limitantes superiores de Conforto Térmico propostos por distintos métodos de definição e, sobretudo, se for considerado que o valor de $29.5^{\circ} \mathrm{C}$ está abaixo da temperatura superficial da pele, que é de aproximadamente $32^{\circ} \mathrm{C}$. Isso garante que o sentido das trocas térmicas, por radiação, a mais incisiva na percepção do estresse térmico, ocorre do organismo humano em direção às superfícies circundantes. Por outro lado, os valores da temperatura do ar interiores, igualmente, mantêmse abaixo dos mesmos $32^{\circ} \mathrm{C}$.

\section{Agradecimentos}

$\mathrm{O}$ autor agradece a profícua parceria realizada entre a Escola de Engenharia de São Carlos (EESC USP) e a PENTAK do Brasil, que forneceram recursos e subsídios necessários à realização do experimento e da própria pesquisa realizada em edificação ocupada.

\section{Referências}

INPE. InfoClima. Boletim De Informações Climáticas, Cachoeira Paulista, v. 8, n.3, mar. 2001.

MONTEIRO, C. A. F. A dinâmica climática e as chuvas do Estado de São Paulo: estudo geográfico sob forma de Atlas. São Paulo: Universidade de São Paulo, Instituto de Geografia, 1973.

VECCHIA, Francisco. Clima e Ambiente Construído: a abordagem dinâmica aplicada ao Conforto Humano. 1977. Tese (Doutorado) - Universidade de São Paulo, São Paulo. 